Technical note

\title{
EVALUATION OF STRAINS AND THICKNESSES OF PIPE ELBOWS ON THE BASIS OF EXPRESSIONS RESULTING FROM THE EU- DIRECTIVE FOR THE CASE OF LARGE AND SMALL DEFORMATIONS
}

\author{
Z. ŚLODERBACH \\ Opole University of Technology \\ Faculty of Applications of Chemistry and Mechanics \\ 45-036 Opole, ul. Luboszycka 7, POLAND \\ E-mail: z.sloderbach@po.opole.pl
}

\begin{abstract}
The relations to calculate the maximum value of strains in processes of bending tubes on benders, in stretched layers of tubes, are presented in this work on the basis of the EU-Directive concerning production of pressure equipment. It has been shown that for large deformations that occur during bending of the pipes on knees, logarithmic strain measures (real) and relative strain measures give different values of strain but equal wall thicknesses in the bending zone. Logarithmic measures are frequently used in engineering practice and are valid for large and small deformations. Reverse expressions were also derived to calculate the required initial wall thickness of the tube to be bent, in order to obtain the desired wall thickness of the knee after bending.
\end{abstract}

Key words: EU Directive, required thicknesses of pipe elbows, pipe bending processes, relative and logarithmic measures of deformation, required initial thickness of a bent tube.

\section{Introduction}

This work is a continuation and development of the works (Śloderbach and Pajak, [1]; Śloderbach [2]), in which concepts of small and large deformations were considered. This work is a synthesis of the results obtained in papers (Śloderbach and Pajak, [1]; Śloderbach [2]).

According to the EU-Directive on requirements in manufacturing of pressure equipment presented in (EN 13445-4, 2009, [3]; Zdankiewicz, [4]) the measure of relative strain is used for calculating the value of deformation (Gabryszewski, [5]; Hill, [6]; Johnson and Mellor, [7]; Lubliner, [8]; Mendelson, [9]; Olszak et al., [10]; Życzkowski, [11]). This is also a measure of the maximum value of the longitudinal component of the strain state for the case of 1-st order simplification (Śloderbach, [12], [13], [14], [15]). In this paper, suitable equations will be derived for the three main components of relative strains, which, according to formula from (EN 13445-4, 2009, [3]; Zdankiewicz, [4]), reach their maximal values. The expression for the minimum value of the wall thickness in the knee bending layer will be derived. During tube bending usually great strains are created (several tens of percent), see (Franz, [16], [17]; Grunow, [18]; Korzemski, [19]; Śloderbach, [12], [13], [14], [15], [20]; Śloderbach and Rechul, [21]; Tang, [22]; Team Work, [23], [24]; Wick et al., [25]; Zhang et al., [26]; Zhiqiang et al., [27]). Then logarithmic measures of strain (logarithmic measures are frequently used in engineering practice and are valid for large and small deformations) will not be equal to the measures of the relative strain. Different values of strains will be obtained from the use of these measures for the case of small and large deformations (Śloderbach and Pajak, [1]; Śloderbach [2]). It will cause differences in the calculations, which will be demonstrated in the respective examples.

For calculating of the state of strain one can you use the expression contained in the EU-Directive, for the purpose of calculating the minimum (acceptable) wall thickness For the case of large strains, according to simplification of the 1-st order (Śloderbach, [12], [13], [14], [15]) it will result that the minimum (acceptable) wall thicknesses will be equal the calculated in the measures of relative and 
logarithmic strains, respectively. Conversely, the required minimum initial thicknesses of the pipes to be bent will be also equal to those calculated in measures of relative and logarithmic strains. For the case of small deformations both values: of components of the strain and wall thicknesses are different (Śloderbach and Pajak, [1]).

The EU-Directive (EN 13445-4, 2009, [3]; Zdankiewicz, [4]) also contains an empirical expression to calculate the required minimum wall thickness in stretched and compressed layers of bent knees. These expressions are identical to the expressions given in papers (Team Work, [23], [24]), except that instead of calculated thickness, the actual thickness is used. The expressions may be useful and can provide some criteria for the selection of an appropriate method (technology) of pipe bending (for example with using drawing or pushing, with or without a mandrel (Franz, [16], [17]; Grunow, [18]; Korzemski, [19]; Wick et al., [25]; Zhang et al., [26]; Zhiqiang et al., [27]). Further discussion and development of this problem will be presented in section 6 .

The aim of this work is to draw attention to the possible ambiguities that may arise from the use of expressions for calculating the deformation of the tube bent according to the EU-Directive. The relationship for calculating the deformation is expressed in measures of relative strains, depending on the $d_{\text {ext }}$ and refers to the stretched layers. According to the given classification, this expression is equal to the modified expression for the longitudinal component for the 1-st order simplification given in (Śloderbach, [12], [13], [14], [15]), when at the points of stretched layers the state of maximum deformation is reached, see (Śloderbach, [12], [13], [14], [15], [20]; Śloderbach and Rechul, [21]). In papers (Śloderbach, [13], [20]) the derivation of expressions for a generalized scheme of deformations was presented, taking into account the shift of neutral axis $y_{0}$ and using the concept of kinematically admissible plastic strain fields of plastic strain. Since a bent tube is a spacial element, three components of strain state: longitudinal, circumferential and radial (in thickness) were derived. The use of kinematically admissible fields of plastic deformation is a simplified, commonly applied method in the technological theory of plasticity. Tube bending is treated as a process dependent on the angle of bending $\alpha_{b}$ as a parameter. The equations obtained in this way describe well the experimental results presented in (Śloderbach, [13], [14]; Franz, [16]; Korzemski, [17]).

The use in this work of the 1-st order simplification derived in (Śloderbach, [12], [13], [14], [15]) instead of the generalized model of strain (Śloderbach, [13], [15], [20]), is due to the fact that the expression in the EU directive corresponds to the expression for maximum elongation component of strain for this simplification. The other two components of strain (circumferential and radial), which are not included in the EU Directive, are the same as in the generalized model (Śloderbach, [13], [15], [20]).

The examples of calculation results in paper show that using the expression valid for large deformations, the values of relative intensity of plastic strain are different from those obtained with the use of logarithmic strain measures (real measures). But the wall thickness at the top of elbows and the required minimum wall thickness of the bent tube are equal. This may cause some problems in the assessment of pipe bending technology and manufacturing of an elbow.

On the other hand, logarithmic measures of strain, due to their practical meaning, are most often used to the calculations of strain state in engineering practice of plastic forming processes and for tube bending (Gabryszewski, [5]; Hill; [6]; Johnson and Mellor, [7]; Lubliner, [8]; Mendelson, [9]; Olszak et al., [10]; Franz, [16], [17]; Gabryszewski and Gronostajaski, [28]; Szczepinski, [29]).

\section{Basic assumptions and geometrical relations}

In papers (EN 13445-4, 2009, [3]; Zdankiewicz, [4]) an expression to calculate the deformation in the stretched layers in the process of tube bending in accordance with the EU-Directive is presented.

$$
O=\frac{d_{e x t}}{2 R_{m}}
$$

where $O$ - longitudinal (axially) tensile strain in relative terms,

$R_{m} \in\left\langle R-y_{0 \max } ; R\right\rangle$ (Śloderbach and Pajak, [1]; Śloderbach, [13], [14], [20]). 
The parameters of the bending process are presented in Figs 1 and 2. As it results from Fig.1, Eq.(2.1) takes into consideration the shift of the neutral bending axis by the mean bending radius $R_{m}$, since in general $R \neq R_{m}$. If $y_{0}=0$, then $R=R_{m}$. There is no unique definition in the Directive for the $R_{m}$. This could be for example the arithmetic or geometric mean of the bending radius $R$ and $\left(R-y_{0 \max }\right)$ or other value in the range $R_{m} \in\left\langle R-y_{0 \max } ; R\right\rangle$.

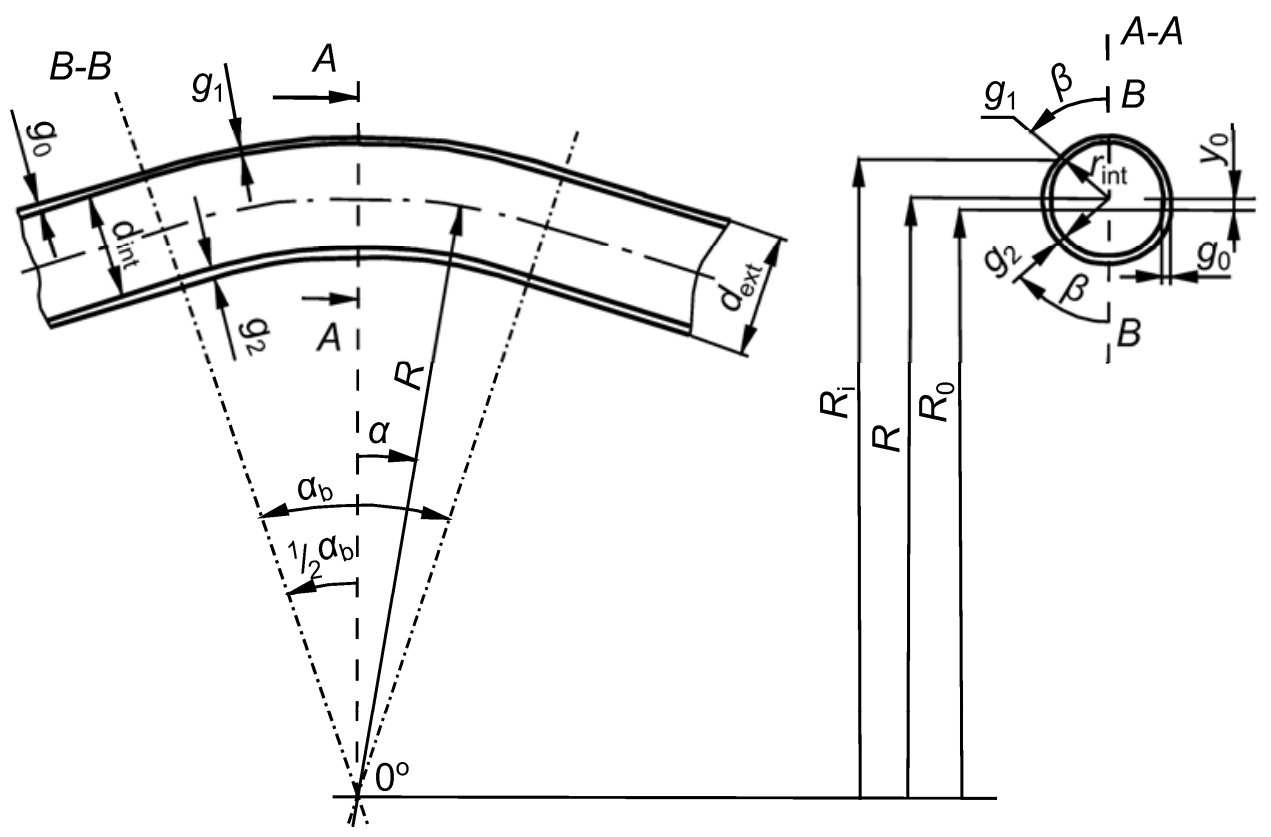

Fig.1. Geometrical and dimensional quantities pertaining to tube-bending processes.

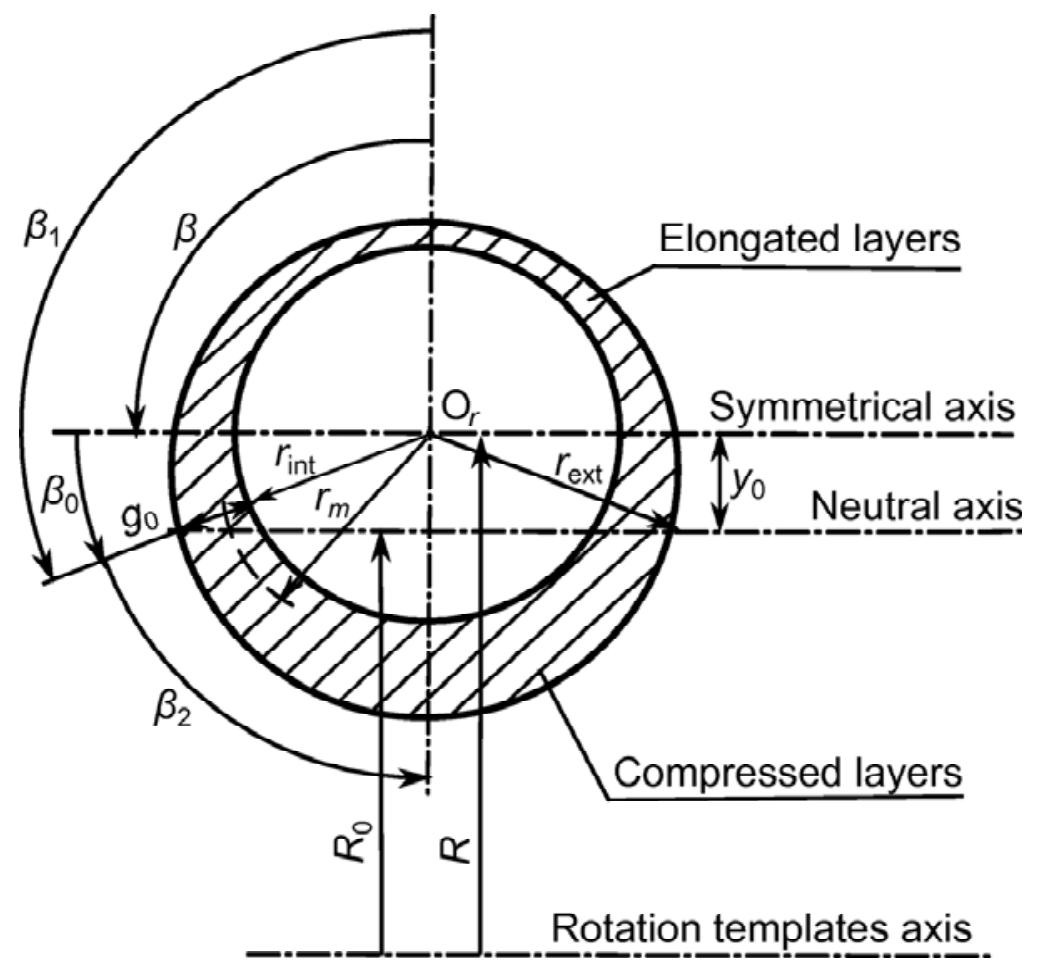

Fig.2. Schematic picture of the elbow cross-section and its characteristic parameters. 


\section{Fundamental relations}

According to the assumptions, see (Śloderbach and Pajak, [1]; Śloderbach, [2], [13], [14], [20]), the derived expressions for strain components in tube bending processes are identified with plastic strains (it appears that in the angular measure of the elastic strains are equal to some degrees (Śloderbach and Pajak, [1]; Śloderbach, [2], [12], [13], [14], [20]). Hence, we obtain that $\varepsilon_{1}^{\prime}, \varepsilon_{2}^{\prime}, \varepsilon_{3}^{\prime}$ - are relative components of plastic deformations for the 1-st order simplification and $\varphi_{1}^{\prime}, \varphi_{2}^{\prime}, \varphi_{3}^{\prime}$ - are logarithmic components of plastic deformations for the 1-st order simplification (Śloderbach and Pajak, [1]; Śloderbach, [2], [13], [14], [15]). Since the bent pipe is spatial, proper analysis of the plastic strain requires the determination of three major components of strain. These components in relative and logarithmic measures according to symbolism accepted in mechanics of solids and according to designations used in papers of (Śloderbach and Pajak, [1]; Śloderbach, [2], [13], [14], [15]), when ( $y_{0}=0$ and formally exchanging $R$ on $R_{m}$ ), for the case of 1 -st order simplification, after transformations have the following forms

$$
\left\{\begin{array}{l}
\varepsilon_{1}^{\prime}=\frac{d_{e x t} \cos \beta_{1}\left(\cos (k \alpha)-\cos \left(k \frac{\alpha_{b}}{2}\right)\right)}{2 R_{m}}, \\
\varepsilon_{2}^{\prime}=\frac{d_{1 r}^{\prime}-d_{e x t}}{d_{e x t}}, \quad \varepsilon_{3}^{\prime}=\frac{g_{1 r}^{\prime}-g_{0}}{g_{0}},
\end{array}\right.
$$

and

$$
\left\{\begin{array}{l}
\varphi_{1}^{\prime}=\ln \frac{2 R_{m}+d_{e x t} \cos \beta_{1}\left(\cos (k \alpha)-\cos \left(k \frac{\alpha_{b}}{2}\right)\right)}{2 R_{m}}, \\
\varphi_{2}^{\prime}=\ln \frac{d_{1 l}^{\prime}}{d_{e x t}}, \quad \varphi_{3}^{\prime}=\ln \frac{g_{1 l}^{\prime}}{g_{0}},
\end{array}\right.
$$

where $d_{1 r}^{\prime}$ and $d_{1 l}^{\prime}$ - the outer minimum diameter of the knee in stretched layers determined for the relative and logarithmic measures (subscript $r$ nad $l$ ) of strain, respectively, where: $d_{1 r}^{\prime}=d_{i n t}+2 g_{l r}^{\prime}$ and $d_{l l}^{\prime}=d_{i n t}+2 g_{l l}^{\prime}, g_{l r}^{\prime}$ and $g_{l l}^{\prime}$ are minimum wall thicknesses of the bent knee in tension layers determined for the relative and logarithmic measures of strain, respectively.

When $\left(\alpha=\beta_{1}=0^{\circ}\right.$ and $\left.k \alpha_{b}=180^{\circ}\right)$, then Eqs (3.1) and (3.2) take their maximum values, as

$$
\varepsilon_{1}^{\prime}=\frac{d_{e x t}}{2 R_{m}}, \quad \varepsilon_{2}^{\prime}=\frac{d_{1 r}^{\prime}-d_{e x t}}{d_{e x t}}, \quad \varepsilon_{3}^{\prime}=\frac{g_{1 r}^{\prime}-g_{0}}{g_{0}}
$$

and

$$
\varphi_{1}^{\prime}=\ln \frac{2 R_{m}+d_{e x t}}{2 R_{m}}, \quad \varphi_{2}^{\prime}=\ln \frac{d_{1 l}^{\prime}}{d_{e x t}}, \quad \varphi_{3}^{\prime}=\ln \frac{g_{1 l}^{\prime}}{g_{0}}
$$


The equations for intensity of plastic deformation for strain measures (3.1), (3.2), (3.3) and (3.4) for the case of large deformations are as follows

$$
\left\{\begin{array}{l}
\varepsilon_{(i) l}^{\prime}=\exp \sqrt{\frac{2}{3}\left(\ln ^{2}\left(1+\varepsilon_{1}^{\prime}\right)+\ln ^{2}\left(1+\varepsilon_{2}^{\prime}\right)+\ln ^{2}\left(1+\varepsilon_{3}^{\prime}\right)\right)}-1, \\
\varphi_{(i)}^{\prime}=\sqrt{\frac{2}{3}\left(\varphi_{1}^{\prime 2}+\varphi_{2}^{\prime 2}+\varphi_{3}^{\prime 2}\right)} .
\end{array}\right.
$$

where:

$\varphi_{(i)}^{\prime}$ and $\varepsilon_{(i) l}^{\prime}$ - intensity of plastic strains in logarithmic and relative measures for large strains (here the additional subscript $l$ at $\varepsilon_{(i) l}^{\prime}$ - means large deformations not logarithmic measure).

The conditions of plastic incompressibility of the material for large strains have the following form

$$
\left\{\begin{array}{l}
\varepsilon_{1}^{\prime}+\varepsilon_{2}^{\prime}+\varepsilon_{3}^{\prime}+\varepsilon_{1}^{\prime} \varepsilon_{2}^{\prime}+\varepsilon_{1}^{\prime} \varepsilon_{3}^{\prime}+\varepsilon_{2}^{\prime} \varepsilon_{3}^{\prime}+\varepsilon_{1}^{\prime} \varepsilon_{2}^{\prime} \varepsilon_{3}^{\prime}=0, \\
\varphi_{1}^{\prime}+\varphi_{2}^{\prime}+\varphi_{3}^{\prime}=0 .
\end{array}\right.
$$

Formulas for calculating the coefficients of the maximum thinning of the tube wall with respect to its initial thickness are as follows (Śloderbach and Pajak, [1]; Śloderbach, [13]; Korzemski, [19])

$$
\left\{\begin{array}{l}
K_{g^{\prime} r}=\frac{g_{0}-g_{l r}^{\prime}}{g_{0}} \\
K_{g^{\prime} l}=\frac{g_{0}-g_{l l}^{\prime}}{g_{0}} .
\end{array}\right.
$$

\section{Calculation of the required minimum wall thickness for large strains}

Substituting components of relative plastic strain (3.3) and (.3.4) to incompressibility conditions (3.6) $)_{1}$ and (3.6) $)_{2}$, respectively, we obtain after transformations the following expression for the appropriate minimum wall thickness of the knee at the apex points of tension layers: $\left(\alpha=\beta_{l}=0^{\circ}\right.$ and $\left.k \alpha_{b}=180^{\circ}\right)$, for the case when $\left(y_{0} \neq 0\right.$ and $\left.R \neq R_{m}\right)$. Hence

$$
\begin{aligned}
& \frac{d_{e x t}}{2 R_{m}}+\frac{d_{l r}^{\prime}-d_{e x t}}{d_{e x t}}+\frac{g_{l r}^{\prime}-g_{0}}{g_{0}}+\frac{d_{e x t}}{2 R_{m}} \cdot \frac{d_{l r}^{\prime}-d_{e x t}}{d_{e x t}}+\frac{d_{e x t}}{2 R_{m}} \cdot \frac{g_{l r}^{\prime}-g_{0}}{g_{0}}+ \\
& +\frac{d_{l r}^{\prime}-d_{e x t}}{d_{e x t}} \cdot \frac{g_{l r}^{\prime}-g_{0}}{g_{0}}+\frac{d_{e x t}}{2 R_{m}} \frac{d_{l r}^{\prime}-d_{e x t}}{d_{e x t}} \cdot \frac{g_{l r}^{\prime}-g_{0}}{g_{0}}=0 \\
& g_{l l}^{\prime}=-\frac{\left(d_{e x t}-2 g_{0}\right)}{4}+\sqrt{\left(\frac{d_{e x t}-2 g_{0}}{4}\right)^{2}+\frac{R_{m} d_{e x t} g_{0}}{2 R_{m}+d_{e x t}}}
\end{aligned}
$$

where $g_{l r}^{\prime}$ and $g_{l l}^{\prime}$ - minimum wall thickness of the bent knee in tension layers determined for the relative and logarithmic measures of strain, respectively and $d_{1 r}^{\prime}=d_{i n t}+2 g_{1 r}^{\prime}$. 


\section{Example 1}

Let the mean bending radius $R_{m}=80 \mathrm{~mm}\left(R_{m} \approx 1.8 \times d_{e x t}\right)$, and the dimensions of the bent pipe: $\phi 44.5 \times 4.5 \mathrm{~mm}$. Based on Eqs (3.3), (3.4) and (4.1) we obtain: $\varepsilon_{1}^{\prime} \cong 0.2781, \varepsilon_{2}^{\prime} \cong-0.0378, \varepsilon_{3}^{\prime} \cong-0.1869$, $\varphi_{1}^{\prime} \cong 0.2454, \varphi_{2}^{\prime} \cong-0.0385, \varphi_{3}^{\prime} \cong-0.2069$ and $g_{1 r}^{\prime} \cong 3.659 \mathrm{~mm}, g_{1 l}^{\prime} \cong 3.659 \mathrm{~mm}$.

Here $g_{l r}^{\prime}$ and $g_{l l}^{\prime}$ are calculated minimum wall thickness of the bent knee in stretch layers expressed in relative and logarithmic measures of strain, respectively. Corresponding to the above calculations coefficients of the thinning, see (3.7), have the following values $K_{g^{\prime} r} \cong 0.187, K_{g^{\prime} l} \cong 0.187$. Then

$$
K_{g^{\prime} r}=K_{g^{\prime} l}
$$

Based on the above results and on Fig.3 we obtain the following equality

$$
g_{1 r}^{\prime}=g_{1 l}^{\prime} \text {. }
$$

For the case of large strains (such strains occur during bending of tubes in stretched layers), see e.g. (Śloderbach, [2], [12], [20]; Śloderbach and Pajak, [1], [35]; Gabryszewski, [5]; Haupt, [30]; Huttel and Matzenmiller, [31]; Pęcherski, [32]; Życzkowski and Szuwalski, [33]; Życzkowski and Tran, [34]) and based on expressions (3.3), (3.4) and (3.5) and equalities (4.2), (4.3), the following inequalities of strains hold

$$
\varepsilon_{1}^{\prime}>\varphi_{1}^{\prime}, \quad\left|\varepsilon_{2}^{\prime}\right|<\left|\varphi_{2}^{\prime}\right|, \quad\left|\varepsilon_{3}^{\prime}\right|<\left|\varphi_{3}^{\prime}\right|,
$$

and

$$
\varepsilon_{(i) l}^{\prime}>\varphi_{(i)}^{\prime}
$$

The above examples of computational results show that the values of relative strains calculated according to the EU-Directive are different from those obtained with the use of logarithmic (real) strain measures. On the other hand, it is known that logarithmic measures of strain, due to their practical properties, are usually used to describe the state of strain in several plastic forming processes, including the pipe bending (Sloderbach and Pajak; [2]; Śloderbach, [13], [15], [20]; Franz, [16], [17]; Grunow [18]; Korzemski, [19]; Śloderbach and Rechul, [21]; Gabryszewski and Gronostajski; [28]; Wick et al. [25]; Szczepiński, [29]). This fact may cause some problems in the tube bending technology, in the production and practical applications.

The values of thinning coefficient of the wall thickness, calculated in Example 1, in all cases exceed the value of acceptable thinning, which, according to Korzemski [19] for this outer diameter of tube, bent with radius $R_{m} \geq 3 \times d_{e x t}$, is equal to $K_{g^{\prime} \text { 'al }}=0.08$. It results from the fact that bending with radius $R_{m} \cong 1.8 \times d_{\text {ext }}$ (as in Example 1) is "sharper". For knees made of thin-walled metal on appropriate benders (with rotating template and during upsetting forces (Śloderbach and Pajak; [2]; Śloderbach, [12], [13], [14], [15], [20]; Franz, [16], [17]; Grunow, [18]; Korzemski, [19]; Śloderbach and Rechul, [21]; Tang, [22]; Team Work, [23], [24]; Wick et al., [25]; Zhang et al., [26]; Zhiqiang et al., [27]) and bent with radius $R_{m} \geq 1.25 \times d_{\text {ext }}$, the thinning of wall can be smaller than $15 \%\left(K_{g},<0.15\right)$. From formulas $(4.1)$ it follows that if the bending radius $R_{m}$ tends to infinity, then the values $\left(g_{1 r}, g_{l l}\right)$ tend to value $g_{0}$, respectively, and that means no bending effect. 


\section{Determination of the required initial thickness of bent tube for large strains}

This issue is the inversed problem to the one considered in the previous section. Now in calculations will be given the required (desired) wall thickness $g_{1}$, for example that fulfils, resistance and construction conditions, technological and operational requirements, EU-PN requirements (PN - Polish Standard) or regulations of the UDT (Office of the Polish Technical Supervision, see (Team Work, [23], [24]). The initial (starting) required thickness $\mathrm{g}_{0}$ of the tube wall to be bent, will be searched.

Substituting the components of plastic strains, relative (3.3) and logarithmic (3.4) respectively, to the incompressibility condition (3.6) and (3.6) $)_{2}$, we obtain after transformations the following expression for the appropriate initial (starting) required thickness of the wall of tube to be bent in the stretched layers

$$
\begin{aligned}
& \frac{d_{e x t}}{2 R_{m}}+\frac{2\left(g_{1}-g_{0 r}^{\prime}\right)}{d_{e x t}}+\frac{g_{1}-g_{0 r}^{\prime}}{g_{0 r}^{\prime}}+\frac{d_{e x t}}{2 R_{m}} \cdot \frac{2\left(g_{1}-g_{0 r}^{\prime}\right)}{d_{e x t}}+\frac{d_{e x t}}{2 R_{m}} \cdot \frac{g_{1}-g_{0 r}^{\prime}}{g_{0 r}^{\prime}}+ \\
& +\frac{2\left(g_{1}-g_{0 r}^{\prime}\right)}{d_{e x t}} \cdot \frac{g_{1}-g_{0 r}^{\prime}}{g_{0 r}^{\prime}}+\frac{d_{e x t}}{2 R_{m}} \cdot \frac{2\left(g_{1}-g_{0 r}^{\prime}\right)}{d_{e x t}} \cdot \frac{g_{1}-g_{0 r}^{\prime}}{g_{0 r}^{\prime}}=0,
\end{aligned}
$$

and

$$
g_{0 l}^{,}=\frac{g_{1}\left(d_{e x t}+2 g_{1}\right)\left(2 R_{m}+d_{e x t}\right)}{2\left[R_{m}\left(d_{e x t}+2 g_{1}\right)+d_{e x t} g_{1}\right]}
$$

where $g_{0 r}$ and $g_{0 l}$ - are the required initial wall thickness values expressed through relative and logarithmic strains, $g_{l}$ - a required (desired) minimum wall thickness of the knee at the apex point of stretched layers $(\alpha$ $=\beta_{1}=0^{\circ}$ ).

\section{Example 2}

Let the mean bending radius $R_{m}=80 \mathrm{~mm}\left(R_{m} \approx 1.8 \times d_{e x t}\right)$, bending angle $\left(k \alpha_{b}=180^{\circ}\right)$, outer diameter of tube $d_{e x t}=44.5 \mathrm{~mm}$ and the required wall thickness of the knee at the apex (middle) point of stretched layers $g_{l}=4.5 \mathrm{~mm}$. Then, on the basis of formulas (5.1) and (5.2) after calculations we obtain: $g_{0 r}=5.459 \mathrm{~mm}$ and $g_{0 l}^{\prime}=5.495 \mathrm{~mm}$.

These are computed required initial wall thickness values, obtained respectively for logarithmic and relative measures of strain, depending on values of the outer diameter of bent tube on the basis of the EUDirective.

On the basis of these results and the plots in Fig. 4 we obtain the following equality

$$
g_{0 r}^{,}=g_{0 l}^{\prime}
$$

The method of calculations is as follows: for given parameters of bending described with the average bending radius $R_{m}$ and for given geometric dimensions of tube to be bent $\left(l \times d_{e x t}\right)$ and for the required value of wall thickness of bent knee $g_{1}$, the required value of initial thickness of the tube to be bent is determined on the basis of expressions (5.1) and (5.2). From formulas (5.1) and (5.2) it also follows that when the bending radius $R_{m}$ tends to infinity, then the values of $g_{0 r}^{\prime}$ and $g_{0 l}$ tend to $g_{l}$ and that means no bending process. 


\section{Calculations for the case of expressions valid for small deformations}

The corresponding expressions for the intensity of plastic deformation and incompressibility of plastic material for the case of small deformations $(<5 \%)$ introduced in relative measures of deformations have the form

$$
\left\{\begin{array}{l}
\varepsilon_{(i)}^{\prime}=\sqrt{\frac{2}{3}\left(\varepsilon_{l}^{\prime 2}+\varepsilon_{2}^{\prime 2}+\varepsilon_{3}^{\prime 2}\right),} \\
\varepsilon_{1}^{\prime}+\varepsilon_{2}^{\prime}+\varepsilon_{3}^{\prime}=0,
\end{array}\right.
$$

where $\varepsilon_{(i)}^{\prime}$ - intensity of plastic deformation for the case of small deformations.

Substituting components of relative plastic strain (3.5), respectively, to incompressibility conditions $(6.1)_{2}$, we obtain after transformations the following expression for the appropriate minimum wall thickness of the knee at the apex points of tension layers: $\left(\alpha=\beta_{1}=0^{\circ}\right.$ and $\left.k \alpha_{b}=180^{\circ}\right)$, for the case when $\left(y_{0} \neq 0\right.$ and $\left.R \neq R_{m}\right)$. Hence,

$$
g_{\text {lrs }}^{\prime}=g_{0}-\frac{g_{0} d_{e x t}^{2}}{2 R_{m}\left(d_{e x t}+2 g_{0}\right)}
$$

where $g_{l r s}$ - minimum wall thickness of bent knee in tension layers determined for the relative measures for the case of small strains (additional subscript $s$ ) and the expression for $g_{l l s}$ - for small deformations has the same form as formula $(4.1)_{2}$, therefore $g_{l l s}^{\prime}=g_{l l}^{\prime}$.

Substituting the components of plastic strains (3.3) to the incompressibility condition $(6.1)_{2}$, we obtain after transformations the following expression for the appropriate initial required thickness of the wall of tube to be bent in stretched layers

$$
g_{0 r s}=\frac{-\left[2 R_{m}\left(d_{\text {ext }}-2 g_{1}\right)-d_{\text {ext }}^{2}\right]}{8 R_{m}}+\frac{\sqrt{\left[2 R_{m}\left(d_{\text {ext }}-2 g_{1}\right)-d_{\text {ext }}^{2}\right]^{2}+32 R_{m}^{2} d_{\text {ext }} g_{1}}}{8 R_{m}}
$$

where $g_{0 r s}$ - the required initial wall thicknes values expressed through relative measures for the case of small deformations (additional subscript $s$ ) and $g_{0 l s}$ - for small deformations has the same form as (5.2), therefore $g_{01 l s}^{\prime}=g_{0 l}^{\prime}$.

$g_{1}$ - the required (desired) minimum wall thickness of the knee at the apex point of stretched layers.

For the case of small deformations the following inequalities hold: see [1] and Figs 3, 4 and 5.

$$
g_{l r s}^{\prime}<g_{l l}^{\prime}, \quad g_{0 r s}^{\prime}>g_{0 l}^{\prime} \quad \text { and } \quad K_{g^{\prime} r s}>K_{g^{\prime} l},
$$

and

$$
\varepsilon_{1}^{\prime}>\varphi_{1}^{\prime}, \quad\left|\varepsilon_{2}^{\prime}\right|>\left|\varphi_{2}^{\prime}\right|, \quad\left|\varepsilon_{3}^{\prime}\right|>\left|\varphi_{3}^{\prime}\right| \quad \text { and } \quad \varepsilon_{(i) s}^{\prime}>\varphi_{(i)}^{\prime} .
$$




\section{Results and discussion}

The minimum thickness changes of the bent knee $\left(g^{\prime}{ }_{l r}, g^{\prime}{ }_{l l}\right.$ and $\left.g_{l r s}\right)$ depending on the average bending radius $R_{m}$, for bent tube with dimensions $\phi 44.5 \times 4.5[\mathrm{~mm}]$, with the use of relative and logarithmic measures of strain, respectively, are presented in Fig.3. As can be seen from the plots, when the bending radius $R_{m}$ decreases, then the differences in the thicknesses are increased (differences between the thicknesses $g^{\prime}{ }_{l r}=g^{\prime}{ }_{l l}$ and thickness $g^{\prime}{ }_{l r s}$ ) and on the contrary, when the bending radius $R_{m}$ goes to infinity, then calculated thicknesses $\left(g^{\prime}{ }_{l r}, g^{\prime}{ }_{l l}\right.$ and $\left.g_{l r s}^{\prime}\right)$ tend respectively to thickness $g_{0}\left(g_{0}=4.5 \mathrm{~mm}\right)$ and that means the lack of bending.

Graphs of initial (required) thicknesses of bent pipes depending on the value of the average bending radius $R_{m}$, when the required (desired) thickness of the wall of the bent knee is $g_{l}=4.5 \mathrm{~mm}$, are presented in Fig.4. Similarly as in Fig.3, it is visible from the plots, when the bending radius $R_{m}$ decreases, then the differences in thicknesses are increased (differences between the initial thickness $g^{\prime}{ }_{0 r}=g^{\prime}{ }_{0 l}$ and thickness $g^{\prime}{ }^{\prime} r s$ ) and on the contrary, when the bending radius $R_{m}$ goes to infinity, then calculated required thicknesses $\left(g^{\prime}{ }_{0 r}, g^{\prime}{ }_{0 l}\right.$ and $\left.\mathrm{g}^{\prime}{ }_{r s}\right)$ tend respectively to thickness $g_{0}\left(g_{0}=4.5 \mathrm{~mm}\right)$ and that means the lack of bending.

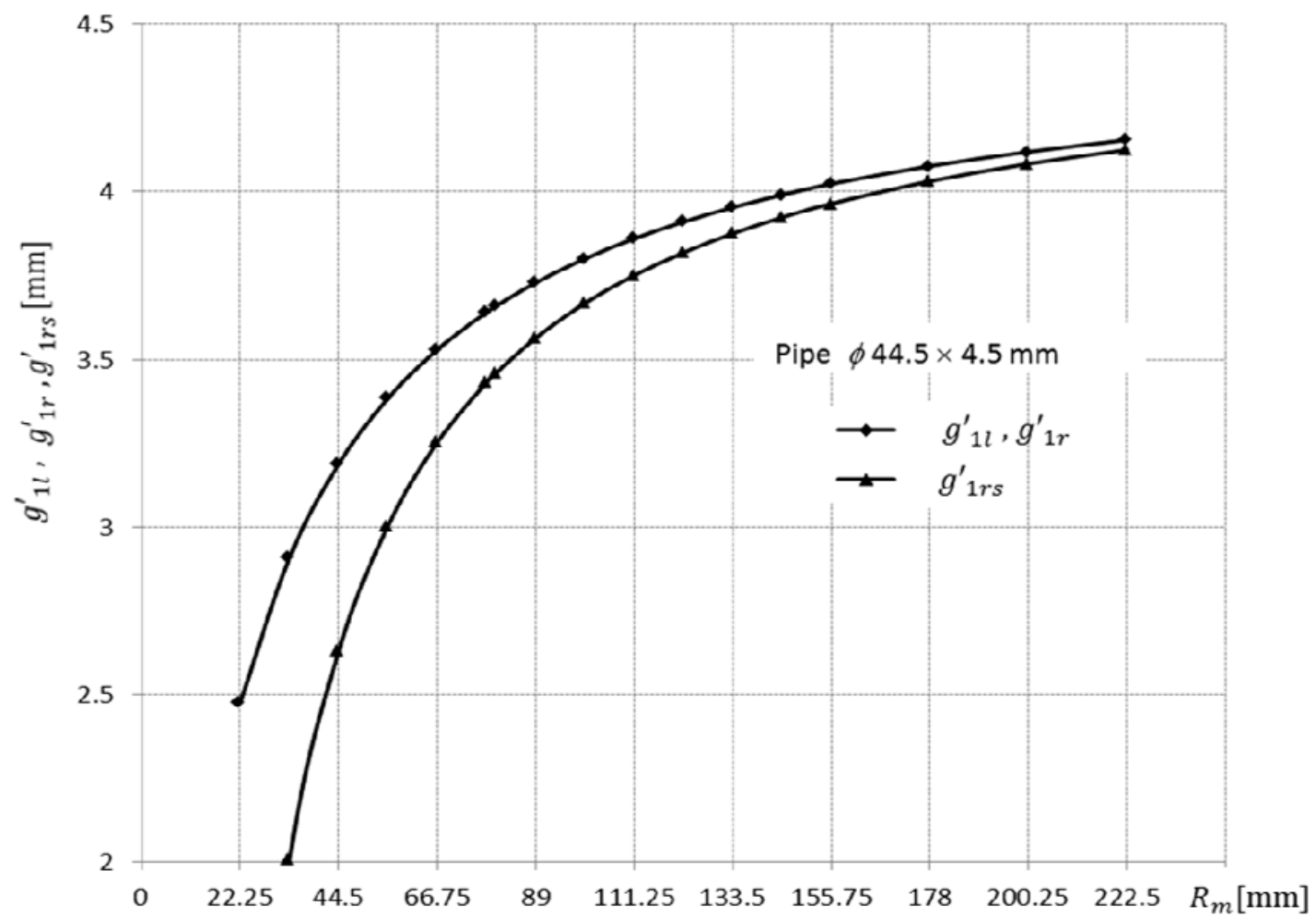

Fig.3. Variation of the minimum wall thickness values $\left(g_{l l}^{\prime}, g_{l r}^{\prime}\right.$ and $\left.g_{l r s}^{\prime}\right)$ of a bend with the bending radius $R_{m}$ for $\phi 44.5 \times 4.5 \mathrm{~mm}$ pipe. 


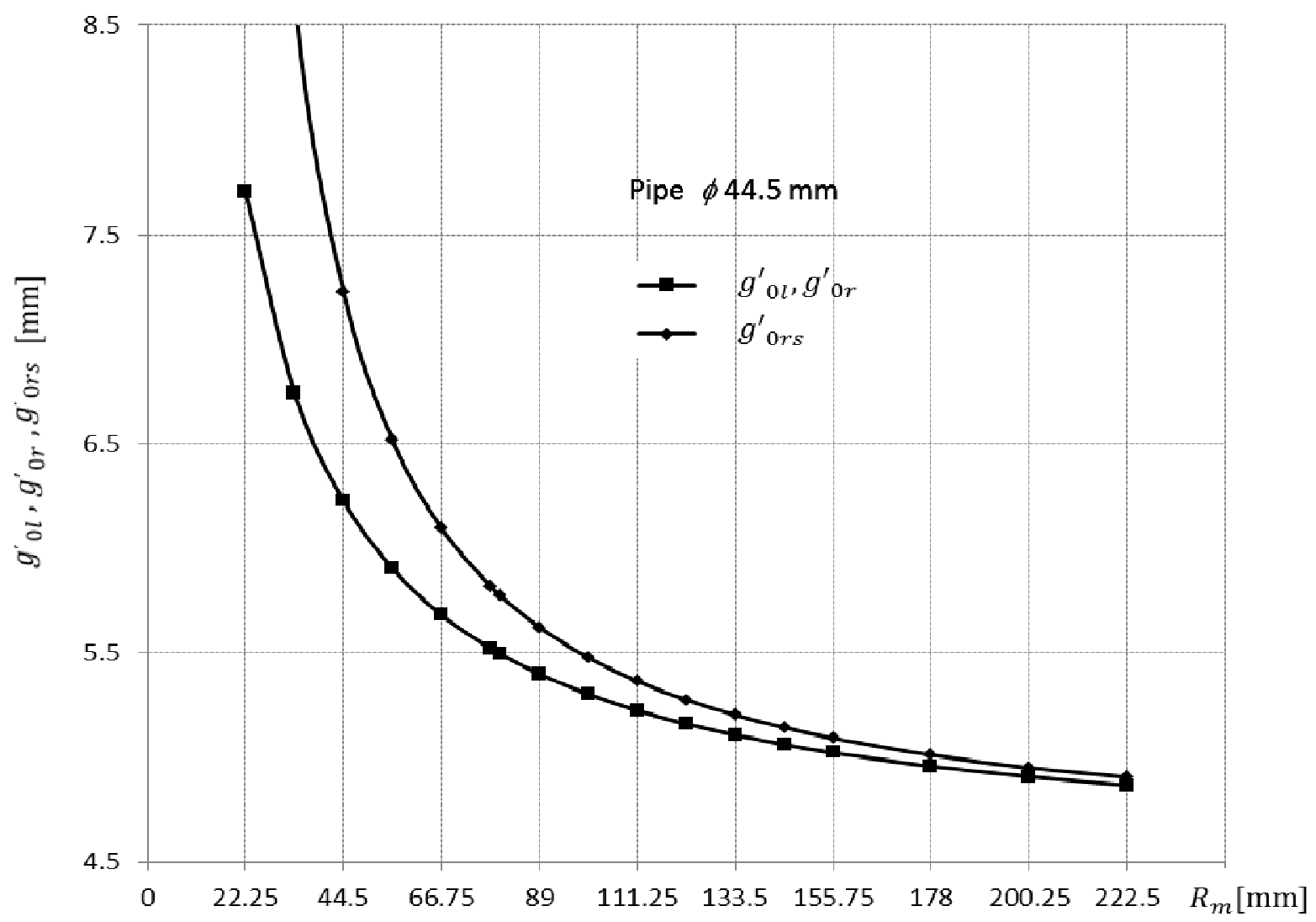

Fig.4. Variation of the initial wall thickness $\left(g_{0 r}^{\prime}, g_{0 l}^{\prime}\right.$ and $\left.g_{0 r s}^{\prime}\right)$ with the bending radius $R_{m}$, if a required minimum wall thickness of a bend for the pipe $d_{e x t}=44.5 \mathrm{~mm}$ is $g_{l}=4.5 \mathrm{~mm}$.

The use of relative and logarithmic measures of strain causes significant differences in the calculations of intensity of plastic strains, see Fig.5. In Fig.5 it can be seen that

$$
\varepsilon_{(i)}^{\prime}>\varepsilon_{(i) l}^{\prime}>\varphi_{(i)}^{\prime} .
$$

When the bending radius $R_{m}$ increases, then the intensity of plastic strains decreases, see Fig.5. When the bending radius $R_{m}$ tends to infinity $\left(R_{m} \Rightarrow \propto\right)$, then the intensity of plastic strains tends to zero $\left(\varepsilon_{(i) l}^{\prime}, \varphi_{i}^{\prime}\right.$ and $\left.\varepsilon_{(i) s}^{\prime} \Rightarrow 0\right)$. The same is for components of deformations. At the end it should be mentioned that equalities (4.2), (4.3), (5.3) and inequalities (4.4), (4.5), (6.4) and (6.5) derived in this work will be also met for each bending radius $R_{m}$ and all geometric dimensions of bent tube and for $\left(R>y_{0 \max }\right)$. The last geometrical condition is always fulfilled in real processes of bending pipes on bending machines.

It was shown in papers (Śloderbach, [13], [15], [20]) that the use of logarithmic (real) measures of strain very well describes (even with accuracy of about $1 \%$ ) experimental data found in (Franz, [16], [17]; Grunow, [18]; Korzemski, [19]) and author's data (Śloderbach, [13]), in both layers, stretched and compressed. 


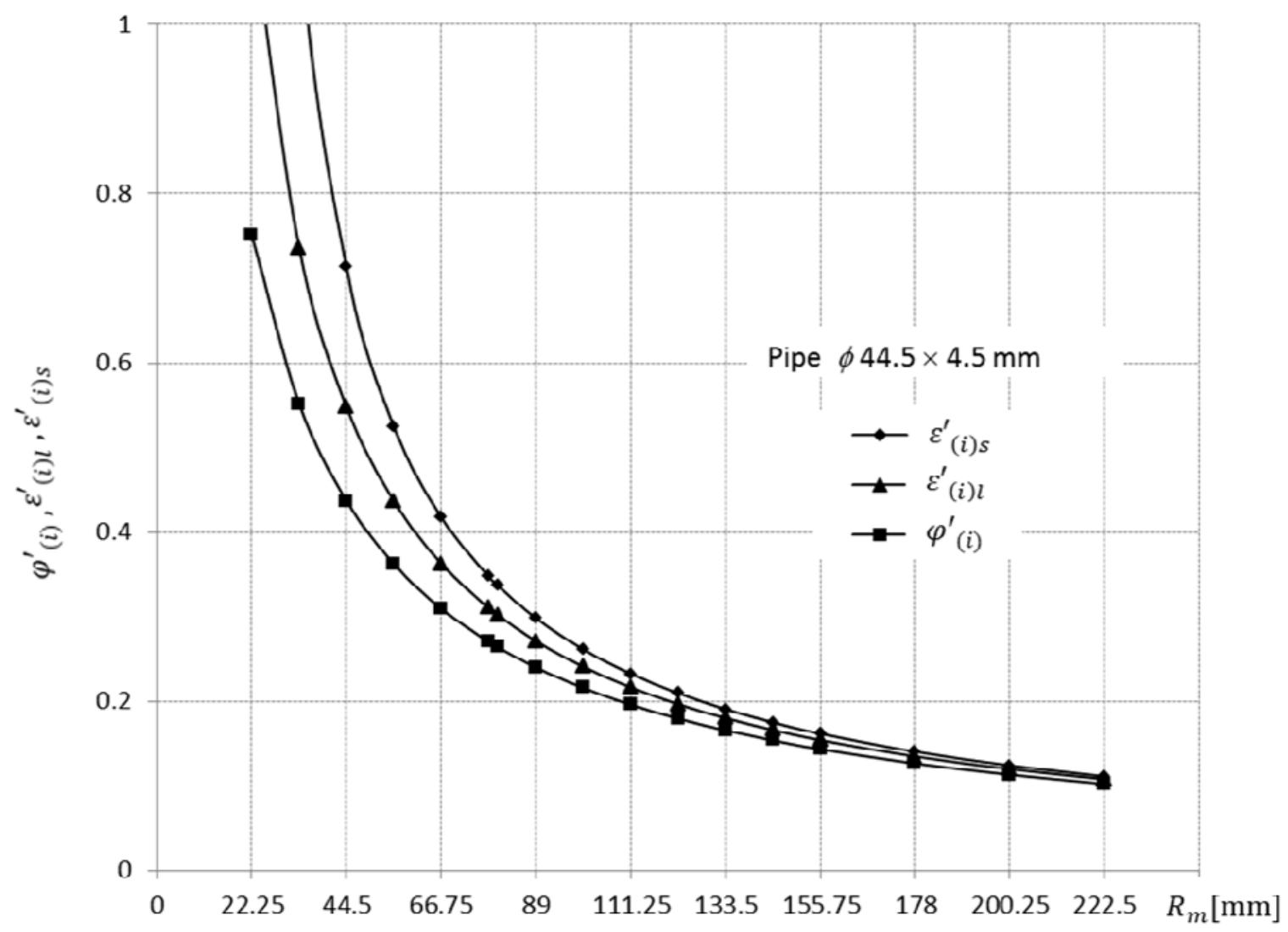

Fig.5. Variation of the intensity of plastic deformation values $\left(\varepsilon_{(i)}^{\prime}, \varepsilon_{(i) l}^{\prime}\right.$ and $\left.\varphi_{(i)}^{\prime}\right)$ of a bend with the bending radius $R_{m}$ for $\phi 44.5 \times 4.5 \mathrm{~mm}$ pipe, where $\boldsymbol{\varepsilon}_{(i) l}^{\prime}$ - denote the intensity of plastic deformation for the case of formulas valid for large (subscript $l$ ) strains $(3.7)_{1}$ and $(3.8)_{1}$.

Adoption of 1-st order simplifications of logarithmic and relative measures of strain provides, in addition to the advantages mentioned previously, very good accuracy of description of experimental data. These simplifications also take into account, during real processes of bending tubes on benders, the effect of even lowering with the angle of bending and mutually proportional (due to the effects of thinning and ovality of cross-section) of the outer stretched layers and simultaneous shifting "downwards" (in the direction of the center of curvature and rotation), see (Śloderbach and Pajak, [2]; Śloderbach, [13], [14], [20]; Franz, [16], [17]; Grunow, [18]; Korzemski, [19]; Śloderbach and Rechul, [21]; Wick et al., [25]) inert layer of plastic bending. During the bending of tubes on a mandrel with a trackpad and using a profiled strip with an adjustable clamp and with minimum clearances between the tools and the walls of the bent pipe, plastically deformed material of the pipe will move more "sideways" and less swell in compression layers, which will cause that actual position of the inert layer will be less moved "downwards", (Śloderbach and Pajak, [1]; Śloderbach, [2], [13], [14], [20]; Franz, [16]; [17], Grunow, [18]; Korzemski, [19]; Tang, [22]; Wick et al., [25]). In the considered case this displacement is not big, and we can write that ( $r_{1} / R_{0} \approx r_{e x t} / R \approx$ const) and $R_{0}$ $=R_{0}\left(\alpha_{b}\right)$. From the tests and analytic calculations it also appears that the radius determining the position of the neutral layer is $\left[R_{0} \approx R-\left(g_{0}-g_{1}\right)\right.$ ], see also (Śloderbach and Pajak; [2]; Śloderbach, [13], [14], [20]; Śloderbach and Rechul, [21]). Due to the occurrence of these effects, in real technological processes of bending pipes, we have some physical justification for the use of simplified expressions of 1-st degree. The simplifications in the formulas for the longitudinal (axial) strain thus contain the value of $d_{e x t}$ instead of $d_{i}$ in the numerator. 


\section{Remarks and conclusions}

1. The above examples of computational results show that the relative intensity of plastic strains is higher (for small and large strains) than this obtained with the use of logarithmic strain measures (real), but the minimum wall thickness is equal. On the other hand, logarithmic measures of strain, due to their practical properties, are most often applied to the description of strain state in many forming processes, including tube bending, see (Śloderbach and Pajak, [1]; Śloderbach, [2], [13], [14], [20]; Franz, [16]. [17]; Grunow, [18]; Korzemski, [19]; Śloderbach and Rechul, [21]; Wick et al., [25]). This fact may cause some problems in designing and technology and also in strength and operation.

2. From inequalities (4.4), (4.5) and (6.4), (6.5) and of graphs in Figs $3-4$ results, that different values of components of plastic deformations and intensity of plastic deformations counted in relative and logarithmic measures give for the case of large strain the same walls thicknesses in bent pipes, but for small deformations different (greater). Values of intensity of plastic deformations are different, see Fig.5.

3. If we assume expressions (6.1) to be valid for small deformations instead of $(3.5)_{1}$ and (3.6) $)_{1}$, then expressions for $g_{1 r}^{\prime}$ and $g_{0 r}$, will have different formulae, see (6.2) and (6.3) such that after calculations $\left(g_{l r s}^{\prime}<g_{l l}^{\prime}\right)$ and $\left(g_{0 r s}^{\prime}>g_{0 l}^{\prime}\right)$, but inequality (6.5) will be still valid, see (Śloderbach and Pajak, [1]; Śloderbach, [2], [13]).

4. In order to obtain the required (in accordance with EU-Directive concerning pressure equipment and its production, included in (EN 13445-4, 2009, [3]; Zdankiewicz, [4]) values of strain and the thickness of bent knees and the initial wall thickness of tubes to be bent for large deformations, we should use the relations (3.3), (4.1) and (5.1) derived in this work and (3.6) 1 . However, for solution for small deformations we should use relations (3.3) and (7.1), see (Śloderbach and Pajak; [1]; Śloderbach, [2], [13]).

5. This work can be treated as an initial step and further steps could involve the development of nomograms and tables for bending tubes of various dimensions $\left(d_{e x t} \times g_{0}\right)$ or $\left(d_{i n t} \times g_{0}\right)$ for various $R_{m}$ applying expressions (3.3), (4.1) $)_{1}$ and (5.1) valid for large deformations. When the initial thickness $g_{0 l}$ or $g_{0 r}$ are calculated depending on $d_{e x t}$ or $d_{i n t}$, the results are different, see (Śloderbach, [2], [13], [15], [36]). The EU Directive contains dependence on $d_{\text {ext }}$ not on $d_{\text {int }}$.

6. The solution of the problem of pipe bending on benders in the framework of nonlinear solid mechanics is difficult due to complex relations between stresses and deformations, see (Gabryszewski, [5]; Haupt, [30], Huttel, and Matzenmiller, [31]; Pęcherski, [32]; Życzkowski. and Szuwalski, [33]) and is open to further studies. We should remember that tube bending is not a straightforward process but depends on the bender, its stiffness, shape of working tools, type of applied mandrels, bending parameters such as $R_{m}$, tube dimensions $\left(d_{e x t} \times g_{0}\right)$, tube material, and others (Śloderbach and Pajak; [1]; EN 13445-4, 2009, [3]; Zdankiewicz, [4]; Śloderbach, [2], [13], [14], [15], [20], [36]; Franz, [16], [17]; Grunow, [18]; Korzemski, [19]; Śloderbach and Rechul, [21]; Wick et al., [25]; Zhang et al., [26]; Zhiqiang et al., [27]).

\section{Nomenclature}

\footnotetext{
$d_{\text {ext }}, d_{\text {int }}$ - are external and internal diameters of a bent tube

$d_{l r}^{\prime}$ and $d_{l l}^{\prime}$ - the outer minimum diameter of knee in stretched layers determined for the relative and logarithmic measures (subscript $r$ nad $l$ ) of strain, respectively, where: $d_{l r}^{\prime}=d_{i n t}+2 g_{l r}^{\prime}$ and $d_{l l}^{\prime}=d_{i n t}+2 g_{l l}^{\prime}$

$g_{l r}^{,}$and $g_{l l}^{,}-$minimum wall thickness of the bent knee in tension layers determined for the relative and logarithmic measures of strain, respectively

$g_{0}-$ initial thickness of a bent tube

$g_{i}$ - actual thickness of a bend within the bending zone $(i=1$ for elongated layers, $i=2$ for compressed layers)

$g_{0 r}$ and $g_{0 l} \quad$ - required initial wall thickness values expressed through relative and logarithmic strains
} 
$g_{1}-$ required (desired) minimum wall thickness of the knee at the apex point of stretched layers $(\alpha=$ $\left.\beta_{l}=0^{\circ}\right)$

$g_{\text {Irs }}^{\prime}-$ minimum wall thickness of the bent knee in tension layers determined for the relative measures for the case of small strains (additional subscript $s$ ) and $g_{l l s}^{\prime}$ - for small deformations has the same form as formula $(4.1)_{2}$

$g_{0 r s} \quad$ - required initial wall thicknes values expressed through relative measures for the case of small deformations (additional subscript $s$ ) and $g_{0 l s}^{\prime}$ - for smalll deformations has the same form as (5.2)

$k$ - technological-material coefficient dependent on the bent tube material and the applied bending technology, determining a bending zone range in the bent zone (Śloderbach, [2], [13], [20]; Śloderbach and Pajak, [1])

$r_{\text {ext }}$ and $r_{\text {int }}$ - external and internal radius of a bent pipe

$r_{\text {int }}=d_{\text {in }} / 2-\left(\right.$ and is assumed that $r_{\text {int }}=$ const $)$

$r_{m}$ - mean radius of the bent tube, $r_{m}=r_{\text {int }}+g_{0} / 2$

$R_{m}$ - mean bending radius $R_{m} \in\left\langle R-y_{0 \max } ; R\right\rangle, R$ - bending radius

$R_{0}$ - radius of the neutral surface following bending, where $R_{0}=R-y_{0}$

$R_{i}$ - larger actual radius of a bend associated with longitudinal strain

$y_{0}$ - displacement of the neutral surface (axis) with respect to the initial position, see (Śloderbach, [2], [13], [14], [20]; Śloderbach and Pajak, [1])

$\alpha$ - actual angle of the bending zone determined at the principal bending plane and at planes parallel to it, $\alpha \in\left\langle 0^{o} ; \frac{\alpha_{b}}{2}\right\rangle$

$\alpha_{b}$ - active bending angle measured over the bending zone, $\alpha_{b} \in\left\langle 0^{\circ} ; 180^{\circ}\right\rangle$

$\beta$ - actual angle determined at the planes perpendicular to the bending plane, that $\beta \in\left\langle 0^{\circ}, 90^{\circ}\right\rangle$

$\beta_{1}$ and $\beta_{2}-$ angle determined in elongated and compressed layers, $\sin \beta_{0}=y_{0} / r_{\mathrm{ext}} \approx y_{0} / r_{m}$,

$\varepsilon_{1}^{\prime}, \varepsilon_{2}^{\prime}, \varepsilon_{3}^{\prime} \quad$ - relative components of plastic deformations for the 1-st order simplification

$\varepsilon_{(i)}^{\prime} \quad$ - intensity of plastic deformation for the case of small deformations

$\varepsilon_{(i) l}^{\prime} \quad$ - intensity of plastic strains in relative measures for large strains (here additional subscript $l$ means large deformations not logarithmic measure)

$\varphi_{1}^{\prime}, \varphi_{2}^{\prime}, \varphi_{3}^{\prime} \quad$ - logarithmic components of plastic deformations for the 1-st order simplification

$\varphi_{(i)}^{\prime} \quad$ - intensity of plastic strains in logarithmic measures

\section{References}

[1] Śloderbach Z. and J. Pajak J. (2015): Determination of the thickness of pipe elbows on the basis of expressions resulting from EU-Directive. - Archive of Applied Mechanics, Springer, vol.85, No.5, pp.629-640.

[2] Śloderbach Z. (2015): Calculations of the strains and thicknesses of pipe elbows on the basis of expressions resulting from the EU Directive for the case of large strains. - Engineering Transactions, vol.63, No.3, pp.361-376.

[3] EN 13445-4. (2009): Unfired Pressure Vessels” - Part 4: Fabrication, (point 9.2.4 Tube Bents, expression 9.2-4), 2009 or earlier: Draft Standart EN UFPV “Unfired Pressure Vessels” - Part 4. "Manufacture”. CEN/TC54/267 JWGB N277, rev. 5 May.

[4] Zdankiewicz M. (1998): European Directive concerning pressure installations. Requirements concerning manufacturing [in Polish]. - Technical Inspection, vol.176, No.2, pp.25-33 and 48.

[5] Gabryszewski. Z. (2001): Theory of elasticity and plasticity [in Polish]. - Publishing House of Wrocław University of Technology, Wrocław.

[6] Hill R. (1985): Mathematical theory of plasticity. - Oxford: At the Clarendon Press.

[7] Johnson W. and Mellor P.B. (1975): Engineering Plasticity. - London: Nostrand Reinhold Company. 
[8] Lubliner J. (1991): Plasticity Theory. - New York: Macmillan.

[9] Mendelson A. (1988): Plasticity-Theory and Applications. - New York: Mc Millan Company.

[10] Olszak W., Perzyna P., Sawczuk A. (1981): Theory of Plasticity. - Warszawa: PWN.

[11] Życzkowski M. (1981): Combined Loading in the Theory of Plasticity. - PWN-Nijhoff, Warszawa-Alpen aan den Rijn.

[12] Śloderbach Z. and Strauchold Sz. (1999): Approximate methods for evaluating strains in pipe bending processes [in Polish]. - Technical Inspection (Dozór Techniczny), vol.1, pp.1-6.

[13] Śloderbach Z. (2002): Some Problems of Mechanics in Pipeline Bending Processes [in Polish]. - Publishing House of Wrocław University of Technology, Wrocław.

[14] Śloderbach Z. (2015): Derivation of relations and analysis of tube bending processes using discontinuous fields of plastic strains. Part I. Derivation of the geometric-analytic relationships. Part II. Discussion and analysis of the obtained results. - International Journal of Applied Mechanics and Engineering, vol.20, No.2, pp.417-435.

[15] Śloderbach Z. (2015): Determination of the initial thickness of a tubes to bending. Part I. Derivation of the basic expressions and relationship. Part II. Discussions and analysis of the obtained results. - Engineering Transactions. vol.63, No.4, pp.481-495, pp.497-507.

[16] Franz W.D. (1961): Das Kalt-Biegen von Rohren. - Berlin: Springer-Verlag.

[17] Franz W.D. (1969): Numerisch gesteuerte Rohrkaltbiegemaschinen. - Werkstatt und Betrieb, vol.9, pp.129-145.

[18] Grunow O. (1985): Praktisches Rohrbiegen. - Berlin: Springer-Verlag.

[19] Korzemski J. (1971): Thin-Walled Pipe Bending [in Polish]. - Warszawa: WNT.

[20] Śloderbach Z. (2014): Genaralized model of strains during bending of metal tubes in bending machines. - Journal of Theoretical and Applied Mechanics, vol.52, No.4, pp.1093-1106.

[21] Śloderbach Z. and Z. Rechul Z. (2000): Effect of strain hardening and normal anisotropy on allowable values of strain and stress in pipe-bending processes. - Journal of Theoretical and Applied Mechanics, vol.38, No.4, pp.843859.

[22] Tang N.C. (2000): Plastic-deformation analysis in tube bending. - International Journal of Pressure Vessels and Piping, vol.77, No.12, pp.751-759.

[23] Team Work. (1991): Technical Requirement. Calculations and checking of wall thickness of bent tubes [in Polish]. - Steam Boilers Factory „RAFAKO” S.A., WT-1/0/R, Racibórz.

[24] Team Work. (2003): Pressure Installations. General Requirements. Strength Calculations [in Polish]. - UDT Conditions, (WUDT-UC-WO-O/02:10), No.1, Warszawa.

[25] Wick Ch. Benedict J.T., Veilleux R.F. (2001): Tool and manufacturing engineers handbook. A reference book for manufacturing engineers, managers and technicans. Forming. Fourth Edition. Society of Manufacturing Engineers, One SME Drive, USA, vol.2, Dearbon, Michigan.

[26] Zhang Z., Yang H., Li H., Ren N., Tian Y. (2011): Bending behaviors of large diameter thin walled CP-Ti tube in rotary draw bending, Progress in Natural Science: Materials International, vol.21, pp.401-412.

[27] Zhiqiang J., Mei Z., He Y., Xudong X., Guangjun L. (2011): Deformation behavior of medium strength TA18 highpressure tubes during NC bending, with different bending radii. - Chinese Journal of Aeronautics, vol.24, pp.657664.

[28] Gabryszewski Z. and Gronostajski J. (1991): Fundamentals of Metal-Working Processes [in Polish]. - Warszawa: PWN.

[29] Szczepiński W. (1987): Theory of Plastic Working of Metals [in Polish]. - Warszawa: PWN.

[30] Haupt P. (2002): Continuum Mechanics and Theory of Materials. - Berlin - Heidelberg: Springer-Verlag.

[31] Huttel C. and Matzenmiller A. (1999), Extension of generalized plasticity to finite deformations and structures. International Journal of Plasticity, vol.36, pp.5255-5276. 
[32] Pęcherski P.B. (1996): Finite deformation plasticity with strain induced anisotropy and shear banding. - Journal of the Materials Processes and Technology, vol.60, pp.35-44.

[33] Życzkowski M. and Suwalski K. (1982): On the termination of the process of finite plastic deformations. - Journal Mécanique Theoretique et Applique, 1, Special Issue, pp.175-186.

[34] Życzkowski M. and Tran L.B. (1997): Interaction curves corresponding to the decohesive carrying capacity of a cylindrical shell under combined loading. - International Journal of Plasticity, vol.13, pp.551-570.

[35] Śloderbach Z. and Pajak J. (2010): Generalized coupled thermoplasticity taking into account large strains: Part I. Conditions of uniqueness of the solution of boundary-value problem and bifurcation criteria. - Mathematics and Mechanics of Solids, vol.15, No.3, pp.308-327.

[36] Śloderbach Z. (2017): Application of the continuous and discontinuous fields of plastic deformations to the evaluations of the initial thickness of bent tubes. - Journal of Engineering Materials and Technology, vol.139, No.1, pp.011009-1 - 011009-10.

Received: January 26, 2017

Revised: September 28, 2017 